\title{
O Programa de Mentoring da PUC Minas: relato de experiência
}

\author{
The Mentoring Program at PUC MINAS: an experience report
}

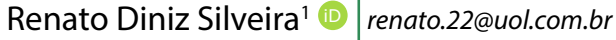

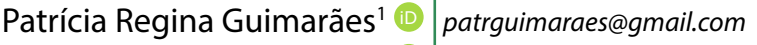 \\ Karla Gomes Nunes ${ }^{1}$ (D) kgnpsico@yahoo.com.br \\ Cláudia Maria Generoso' ${ }^{1}$ (D) claudia.generoso@yahoo.com.br
}

\begin{abstract}
RESUMO
Introdução: O artigo visa relatar a experiência do Programa de Mentoring do curso de Medicina da PUC Minas em Betim, em Minas Gerais, destacando algumas concepções, desafios e potencialidades do percurso de quase uma década. $O$ ato educativo é um estímulo à emancipação do ser humano e às suas potencialidades, e os programas de mentoring representam um potente catalisador desse processo.

Relato de experiência: O Programa de Mentoring da PUC Minas é uma atividade obrigatória, que oferece ao discente um espaço de acolhimento, reflexão e cuidado por meio da referência de um professor mentor. Com horas de dedicação, o mentor acompanha uma turma ao longo do curso, estabelecendo encontros regulares com a turma inteira - no início e final do semestre - e frequentes com grupos menores no decorrer do semestre. Encontros individuais acontecem conforme a demanda do acadêmico. Nos encontros, discutem-se temas referentes ao cotidiano das instituições de saúde e aos desafios enfrentados por elas, de modo a promover o desenvolvimento da identidade médica. Ao mentor cabe atentar aos impasses que se colocam no processo de formação, especialmente sobre a saúde mental dos alunos.

Discussão: No percurso do Programa de Mentoring da PUC Minas, percebem-se sua consolidação na instituição, seu papel na formação dos alunos e o aprendizado dos mentores. Observa-se que não basta apenas formalizar um programa, mas também é necessário disseminar uma cultura de cuidado coerente com os princípios do projeto pedagógico do curso, as Diretrizes Curriculares Nacionais do Curso de Graduação em Medicina e as necessidades do campo da saúde coletiva. Encontra-se aí o desafio de sustentar no perfil do egresso um profissional capacitado tecnicamente e em condições de cuidar de si e daquele que acolhe.
\end{abstract}

Conclusão: Com a implementação do Programa de Mentoring, percebe-se a criação, na instituição, da cultura de mentoring, refletido nas relações entre alunos e professores, possibilitando uma formação que contemple, além dos aspectos técnicos, a essência do cuidado.

Palavras-chave: Tutoria; Educação Médica; Acolhimento.

\begin{abstract}
Introduction: This article reports on the experience of the mentoring program of the PUCMINAS Medicine Course in Betim, Minas Gerais. It highlights concepts, challenges and capabilities of this almost decade-old course. Education stimulates the emancipation of human beings and their potential, and mentoring programs are a powerful catalyst for this process.

Experience report: The PUC Minas mentoring program is a mandatory activity, offering the student a space for welcoming, reflection, and care, conveyed by a teacher mentor. With hours of dedication, the mentor accompanies a class throughout the course by establishing regular meetings - with the whole class at the start and end of the semester, and with smaller groups frequently during the semester. Individual meetings take place according to the student's demand. At the meetings, themes related to the daily routine in health institutions and related challenges are discussed, promoting the development of a physician's identity. The mentor pays close attention for any deadlocks that arise in the training process, especially regarding student mental health.
\end{abstract}

Discussion: Since it was introduced, the mentoring program at PUC Minas has become a consolidated element of the institution, playing an important role in the students' training and the mentors' learning. Formalizing the program is only the first step of the process, it is also necessary to disseminate a culture of care consistent with the principles of the course's pedagogical project, the Curricular Guidelines for Medical Training and public health needs. Therein lies the challenge of achieving the graduate profile of a technically trained professional who is in a position to take care of himself and those he welcomes into the profession.

Conclusion: The implementation of the mentoring program has generated a noticeable culture of Mentoring at the institution, reflected in the relationships between students and teachers, supporting a training that consists not only of technical aspects, but also the essence of care.

Keywords: Tutoring; Medical Education; Host.

${ }^{1}$ Pontifícia Universidade Católica de Minas Gerais, Belo Horizonte, Minas Gerais, Brasil.

Editora: Patrícia Lacerda Bellodi

Recebido em 03/03/21; Aceito em 31/03/21.

Avaliado pelo processo de double blind review. 


\section{INTRODUÇÃO}

As necessidades contemporâneas no campo da educação médica apontam para um reposicionamento do processo ensino-aprendizagem voltado para a realidade brasileira. Esse movimento requer a construção de novas formas de estimular um ensino médico mais atual, mais vivo e mais dinâmico, que procure contribuir para uma prática que realmente tenha impactos sobre a qualidade dos futuros médicos do país. Se esses imperativos são claros para a nossa percepção, mudar essa realidade implica um esforço de atenção especializada à questão da formação médica e à atualização teórico-prática da atividade docente.

Se queremos repensar o trabalho do médico na relação com seu paciente, precisamos nos atentar aos processos que permeiam a dinâmica do ensino-aprendizagem. $O$ ato educativo é, antes de tudo, um estímulo à emancipação do ser humano dentro das suas possibilidades com ênfase nas suas potencialidades, como apontam as Diretrizes Curriculares Nacionais do Curso de Graduação em Medicina'. Partindo dessas premissas, observa-se que o lugar pretendido pelas urgências das demandas de habilidades e competências médicas exige que o itinerário formativo seja problematizado no cerne da estruturação acadêmica, no qual o professor é um facilitador e o aluno o verdadeiro construtor do conhecimento, principalmente se admitirmos que o eixo epistêmico de tratamento da informação é o pensamento complexo, que norteará o raciocínio nas futuras tomadas de decisões. No bojo desses intentos, os programas de mentoring se constituem em um potente catalisador para que isso aconteça quando se consideram as necessidades e os desafios colocados aos estudantes em seu processo de formação acadêmica.

No contexto da formação médica, o processo de aprendizagem é longo e exigente, havendo um elevado índice de sofrimento psíquico dos estudantes, conforme observado por alguns estudos ${ }^{2}$. Considerando essas circunstâncias, várias instituições de ensino têm disponibilizado ações de apoio aos alunos. Bellodi et al. $^{3}$ destacam que essas ações de suporte podem ir desde uma proposta mais focalizada e assistencial até formas mais abrangentes e desenvolvimentistas, tais como a qualidade da vida no campus, a organização do processo ensino-aprendizagem, entre outras, estando o mentoring nessa segunda modalidade.

Nessa perspectiva, visa-se uma formação que considere tanto a qualidade técnico-científica quanto a dimensão sociocultural e o compromisso ético inerente à atuação profissional, propiciando o crescimento pessoal do aluno. Sendo assim, as autoras apontam que a aprendizagem alcança uma dimensão qualitativamente mais elevada ao considerarem que o ato de "educar é também cuidar". Nessa via, o mentoring pode contribuir para o processo de aprendizagem por considerar a complexidade do pensamento e dos afetos aí envolvidos, podendo ampliar a rede de apoio ao aluno acompanhando-o no seu desenvolvimento tanto profissional quanto pessoal. A definição de mentoring carrega um acompanhamento longitudinal do aluno, sendo "uma modalidade especial de relação de ajuda em que uma pessoa mais experiente acompanha de perto, orienta e estimula - a partir de sua experiência, conhecimento e comportamento - um jovem iniciante em sua jornada no caminho do desenvolvimento pessoal e profissional" ${ }^{\prime \prime}$.

Oriundos das escolas de Enfermagem, os programas de mentoring chegaram ao campo da educação médica em 1990, principalmente nos Estados Unidos e na Inglaterra4. Não são poucas as aplicações práticas dessa atividade, podendo ter variados formatos e objetivos, conforme as escolhas de cada escola médica. Podem-se observar efeitos importantes dessa atividade, e alguns aspectos se destacam durante o percurso de um aluno que recebe como oferta o apoio de um mentor durante seu curso. Muitos estudos indicam que alunos mentorados apresentam uma satisfação com a profissão mais perceptível na carreira futura, além da redução de risco para a ocorrência da síndrome de burnout, e a percepção de que efetivamente há um suporte para o desenvolvimento da profissão e da caminhada acadêmica ${ }^{5}$.

Ramanan et al. ${ }^{6}$ conduziram um estudo relevante sobre o processo tutorial na residência médica, visando identificar a relação do preparo profissional e da tutoria entre os residentes de cinco hospitais afiliados à Faculdade de Medicina de Harvard. Os resultados apontaram que $93 \%$ dos residentes consideraram importante ter um tutor durante a residência médica, mas cerca da metade deles não teve. Residentes que participavam de programas tutoriais descreveram a experiência como positiva para o desenvolvimento profissional, fato corroborado pela expressiva porcentagem que afirmou ter recebido conselhos úteis sobre a carreira e o exercício da profissão.

Diante da variedade de formatos e objetivos do mentoring, relataremos a especificidade dessa atividade no curso de Medicina da Pontifícia Universidade Católica de Minas Gerais (PUC Minas) como uma forma de ensino pelo cuidado.

\section{RELATO DE EXPERIÊNCIA}

No caso da PUC Minas, o mentoring tem como um de seus princípios básicos o estabelecimento de uma referência, localizada na presença de um professor que acompanhará a mesma turma ao longo dos seis anos de graduação, acolhendo dificuldades, impasses e conflitos, sejam coletivos ou individuais.

O mentor deve ser docente do curso de Medicina, apresentar perfil acolhedor e que reflita princípios esperados 
na formação humanística do profissional egresso do curso. A seleção dos primeiros mentores se deu basicamente por convite direto do coordenador do Programa de Mentoring, segundo critérios descritos. Quando uma turma se forma, tendo cumprido adequadamente a sua função, o respectivo mentor é convidado para assumir a mentoria dos alunos que estão entrando no curso no semestre seguinte. Parte-se da ideia de que a experiência de 12 meses de seguimento de uma turma traz oportunidade única de aperfeiçoamento do mentor. Quando não é possível ou não há desejo de permanência na mentoria, é aberto um concurso interno para preenchimento da vaga. A seleção consta de uma carta de intenção, currículo e entrevista com a banca constituída pelo coordenador do Programa de Mentoring e por dois outros professores mentores.

A formação do mentor se dá por meio de leituras orientadas pelo coordenador do programa antes e durante a mentoria, reuniões mensais com todo grupo de mentores da PUC Minas, dos três campus em que há o curso de Medicina, além da formação que se dá durante a atividade, com canal aberto com o coordenador e demais mentores para resolução de questões pontuais. A heterogeneidade de experiências é compartilhada entre os mentores, e, semelhante ao que se dá no curso de Medicina, há o aprendizado construído no fazer.

Idealmente o mesmo mentor seguirá um grupo de aproximadamente 60 alunos ao longo dos 12 semestres de curso. Eventualmente há necessidade de substituição de profissionais por motivos diversos, como adoecimentos, saída da instituição, desejo do professor. Houve algumas situações de mudança de mentor desde a implantação do programa, mas em todas foi possível, com os alunos e a equipe, chegar a uma decisão que permitiu a continuidade da mentoria. É interessante notar que, segundo experiências até o momento, percebeu-se que foi possível contornar a situação sem prejuízos no seguimento dos alunos.

Os encontros são planejados no início de cada semestre, dentro da disponibilidade de horário da turma. As reuniões são obrigatórias, e há uma porcentagem mínima de assiduidade. Além de ser uma atividade obrigatória para o discente, gera horas complementares de curso importantes para a conclusão dele. Os professores são remunerados pelas horas de dedicação às atividades de mentoring.

São agendados encontros com toda a turma, geralmente no início e no final dos semestres, e encontros semanais, em que grupos de alunos vão se alternando nos encontros com o mentor. Os encontros com toda a turma acontecem com objetivo de interação, entrosamento e abordagem de questões coletivas. Os grupos são constituídos por aproximadamente de dez alunos, variando de seis a oito grupos. São feitos no mínimo quatro encontros com cada grupo no semestre. Não há uma agenda fixa de temas a serem tratados de forma obrigatória, mas os mentores discutem assuntos relevantes à formação médica. São abordados assuntos relacionados ao curso, à formação médica e ao trabalho médico, tais como: empatia, sexualidade e diversidade, comunicação de notícias difíceis, morte de pacientes, perspectivas com o trabalho médico, entre outros. Também são discutidos aspectos relacionados aos casos trazidos pelos alunos, a partir das suas vivências nos cenários de práticas, possibilitando o acolhimento de angústias geradas a partir da clínica e a reflexão tão necessária ao processo de aprendizado. Há liberdade para que o mentor construa, com os alunos e a partir das necessidades e dos interesses deles, o percurso teórico em cada semestre. E como há um contato próximo dos mentores entre si, com os coordenadores do curso e do mentoring, com alunos mentorados e demais, além do Núcleo de Apoio Psicopedagógico (NAP), é possível alinhamentos, sempre que necessário. Muitos encontros não seguem uma temática específica, preestabelecida ou não, e é possível uma roda de conversa com os alunos de uma forma livre, com trocas de experiências tanto do campo pessoal quanto relacionadas ao curso. Observa-se ainda que dificuldades de relacionamento entre os alunos podem trazer prejuízos à convivência durante as aulas teóricas e práticas, dificultando o aprendizado, e o mentoring se mostra um espaço importante para a abordagem dessas situações.

A pandemia trouxe desafios adicionais à atividade de mentoring, exigindo adaptações e atenção redobrada dos mentores em um cenário incerto e gerador de angústias. Os encontros com pequenos grupos, com toda a turma e individualmente foram mantidos no espaço virtual. Pandemia, risco de morte de familiares, mudanças com o ensino remoto e frustrações com a falta das atividades práticas e do contato presencial foram assuntos frequentes nos encontros, possibilitando acolhimento e reflexão.

Os encontros individuais são agendados a partir das demandas dos mentorados e mentores ou por conta de alguma situação específica percebida por funcionários, professores e/ ou alunos. $\mathrm{O}$ encontro individual permite que questões mais pessoais sejam abordadas com a privacidade necessária, como dificuldades nos estudos, carências financeiras ou mesmo demandas relacionadas à saúde física ou psíquica dos discentes. Com frequência, situações da vida pessoal dos alunos, que impactam diretamente o aprendizado, são trazidas para encontros individuais com o mentor, que pode ser um ponto de apoio ao jovem durante a sua formação. Diante de algum caso mais complexo, a equipe do NAP é acionada e uma rede de cuidado é tecida a partir de cada caso.

Ao longo da graduação, o mentoring oferece e sustenta um espaço de reflexão, e a apresentação do Memorial 
Reflexivo pelo aluno constitui uma marca importante na conclusão do curso. $\mathrm{O}$ aluno deve apresentar, no $12^{\circ}$ período, à banca constituída pelo mentor e por um ou dois professores convidados pelo aluno, à comunidade acadêmica, aos familiares e aos amigos, o seu percurso acadêmico de forma reflexiva. Os portfólios que são construídos ao fim de cada internato, obrigatórios para a conclusão dessa etapa, servem como uma referência, mas o memorial vai muito além - trata-se do processo de elaboração de todo percurso. O ponto a partir do qual o aluno escolhe iniciar a sua narrativa é livre e varia desde a infância, momento de decisão pela medicina ou entrada na faculdade. Muitos falam da saída da cidade de origem, do afastamento da família, dos amigos e dos laços amorosos, das adaptações necessárias à nova realidade para a concretização de um sonho. Na apresentação, o aluno descreve sua trajetória durante a graduação, destacando os pontos importantes. Mencionam-se professores, disciplinas, atividades acadêmicas, amigos, viagens, encontros marcantes com pacientes e com a vivência da clínica, enfim, experiências que marcaram a sua formação. Deve haver um destaque acadêmico: monitoria, pesquisa, artigo publicado, trabalho de extensão, entre outros. A apresentação consiste principalmente em fotos e registros diversos dos acontecimentos mais relevantes. Quando o aluno encerra a sua exposição, a banca de professores faz perguntas relacionadas à apresentação e comentários sobre o discente e seu percurso na instituição. Para que o aluno seja aprovado, o aspecto reflexivo do seu memorial deve ter sido contemplado. Ao final, a palavra é aberta para quem quiser se expressar. Nesse momento, o aluno tem a oportunidade de ouvir depoimentos de familiares e amigos. O testemunho dado pelo aluno do caminho percorrido, acompanhado de reflexões sobre o processo da sua formação, recebendo as impressões de professores de referência para ele, diante de pessoas importantes nos âmbitos pessoal e acadêmico, permite a conclusão do curso de forma singular. As apresentações dos Memoriais Reflexivos foram temporariamente suspensas em decorrência da pandemia, antecipação da conclusão da formatura e necessidade de distanciamento social. Foi feito convite aos alunos que se formaram nesse contexto para retorno à instituição e apresentação, assim que possível.

Na PUC Minas, o Programa de Mentoring foi pensado já na elaboração do projeto pedagógico do curso de Medicina que iria nascer em 2012. Desse modo, procurou-se, desde o início, encontrar um lugar para o mentoring que fosse previsto no cotidiano do discente como a oferta de suporte acadêmico e de desenvolvimento de habilidades profissionais, mas que não chocasse com a grade horária e a agenda dos estudantes. Ainda em sua fase de formulação, o programa já previa auxiliar o discente a organizar o próprio tempo. Na revisão de diversos programas de mentoring, os primeiros desafios encontrados diziam respeito ao grande número de estudantes de Medicina em cada sala e também à falta de adesão ao programa longitudinalmente, sobretudo quando se considera a duração do curso de 12 semestres ${ }^{7}$.

Para o impasse do grande número de acadêmicos, a saída construída, no contexto da PUC Minas, foi a vinculação do professor mentor ao Programa de Mentoring mediante a concessão de horas de dedicação. Desse modo, tornou-se viável a proposição de encontros com grupos menores de alunos. Essa estratégia visa aproximar o professor mentor dos seus alunos desde o primeiro período, favorecendo uma relação de confiança que encontra na reflexão cotidiana a base para o estabelecimento de um vínculo mais profundo. Com encontros semanais, chamados de sessões de mentoring, espera-se que o aluno, de forma gradativa, se aproxime subjetivamente do seu mentor, transformando experiências comuns ao discente em oportunidades de aprofundamento ético e filosófico, contribuindo para que ele construa uma identidade profissional a partir de suas potencialidades, atentando-se ainda para suas limitações emocionais, para possíveis preconceitos velados e dificuldades de relacionamento.

De maneira geral, os programas de mentoring apresentam dificuldades em relação à adesão dos alunos às sessões. Nesse ponto, é preciso ressaltar os desafios que se localizam na dificuldade contemporânea de reflexão pessoal apresentada por jovens adultos. Diante disso, o Programa de Mentoring da PUC Minas é apresentado como obrigatório. Entende-se por obrigatório não a necessidade de participação ativa nas sessões, mas é requerida a presença do aluno. Nesse sentido, pressupõe-se como obrigatória a necessidade de frequentar um espaço onde ocorre o exercício solidário de promover oportunidades de diálogo e reflexão. Espaço que toma consistência nas palavras de um mentorado: “Eu pensava que, se não fosse necessário vir, eu não viria. Agora que eu vi o que é e como fui tratado, estou aliviado por essa obrigação de pensar em mim e nas coisas que faço ou deixo de fazer". Em que pese a obrigatoriedade, existe flexibilidade para as ausências ocasionais. Da mesma forma, no dispositivo oferecido, há espaço para a busca de quem está mais ausente, e não foram poucas as vezes em que o efeito de busca foi interpretado como cuidado: "Que bom que você perguntou por mim", disse um aluno ao ser procurado pelo mentor.

\section{DISCUSSÃO}

No Programa de Mentoring da PUC Minas, a ideia central que orienta o trabalho do mentor é de que não é possível "ensinar" noções de cuidado e acolhimento apenas de modo teórico, pois isso pressupõe a vivência dessa 
experiência diretamente com o aluno, no movimento de acolher e ampará-lo na sua caminhada. Essa vivência pode ser depreendida a partir do que disse um aluno ao seu mentor, dois anos após sua formatura: "Preciso falar com você, me ligue. Eu não deixei de ser mentorado porque me formei, viu?". Frequentemente, torna-se possível registrar os efeitos importantes produzidos entre alunos e professores envolvidos nesse processo. Com efeito, o mentoring consiste em um tipo especial de relação baseada em confiança entre uma pessoa mais experiente e um jovem iniciante, auxiliando este último em seu desenvolvimento pessoal e profissional. Visa, assim, à produção de um sujeito autônomo, mas, ao mesmo tempo, solidário consigo e com o outro.

Ao demarcar como sua finalidade o favorecimento da formação da identidade médica orientada pelo cuidado, o mentoring vincula-se estrategicamente ao colegiado pedagógico do curso, aos professores de todos os períodos, aos alunos e ao NAP. No caso da PUC Minas, o grupo inicial que implementou o programa definiu como objetivo norteador o desenvolvimento crescente da identidade médica, com todas as complexidades que envolvem esse crescimento. A partir desse objetivo, esse grupo começou a recolher as potencialidades e também os obstáculos que foram aparecendo, sempre à luz da realidade local e em consideração às possibilidades de cada professor mentor. Atualmente, constitui-se um grupo com 18 mentores. Nas constantes reuniões entre os mentores, sempre em conjunto com o NAP, são delineados os principais entraves dessa experiência. No entanto, as experiências compartilhadas mostram soluções e caminhos.

De maneira geral, segundo Gonçalves et al. ${ }^{8}$, o mentoring pode ser considerado um processo, com uma sucessão de fases, em que um estágio leva ao próximo, cuja base é a relação mentor-aluno. Além disso, é um processo de ajuda, pois o aluno terá que enfrentar diferentes momentos de sua história no contexto de seu curso, o que se torna mais suportável quando ele pode contar com um espaço de reflexão estabelecido como um programa institucional.

Como referido, no caso da PUC Minas, o mentoring é uma atividade obrigatória, com carga horária de 360 horas, representando $42,90 \%$ das atividades complementares de graduação necessárias para a conclusão do curso, sendo uma das condições indispensáveis para a colação de grau. Como já mencionado, esse fato teve impacto positivo sobre a adesão dos alunos ao programa. Se a carga horária é definida institucionalmente, o conteúdo das atividades é livre, devendo ser construído entre o mentor e seus alunos. Como produto final de cada semestre, o aluno e o mentor escrevem suas reflexões sobre os momentos vividos durante essa trajetória.

\section{CONCLUSÃO}

O Programa de Mentoring da PUC Minas desde a sua implantação tem se aperfeiçoado, mantendo-se em constante processo de construção, com a participação ativa de alunos, docentes e do NAP. A pandemia exigiu maior atenção dos mentores para a manutenção dos encontros e adaptações necessárias ao momento epidemiológico.

Ao longo de quase uma década do Programa de Mentoring da PUC Minas, percebem-se sua consolidação na instituição, seu papel na formação dos alunos e o aprendizado do grupo de mentores. Assim, o processo de implementação do programa requer a negociação com a própria universidade, pois a remuneração dos mentores é determinante para que o acompanhamento destinado aos alunos se desenvolva longitudinalmente. Posterior à implementação desse programa, implementa-se o NAP, desempenhando importante função de apoio às atividades do primeiro. Trata-se de uma estratégia de cuidado formada por um grupo de professores vinculados à coordenação do curso e aos mentores, disponível para apoiar estes últimos e os discentes em situações mais complexas, as quais envolvem, sobretudo, a emergência do sofrimento psíquico. Contudo, a posição ocupada pelo NAP pressupõe o fortalecimento do lugar de referência do mentor, operando por meio da corresponsabilidade e da construção coletiva das saídas necessárias para cada situação.

No nosso contexto, percebe-se a criação da cultura de mentoring que se reflete nas relações entre alunos e professores, de modo a possibilitar uma formação que contemple, além dos aspectos técnicos fundamentais, a essência do cuidado. O pressuposto de ensinar o cuidado em ato traduz-se em uma prática que, ao longo dos anos, constitui uma narrativa em torno da formação médica e de seu exercício pautados pelo cuidado de si e do outro. Com efeito, o Programa de Mentoring beneficia também os professores envolvidos, na medida em que estimula a reflexão contínua do que se está praticando. Novas fronteiras se abrem ao professor mentor a partir dessa atividade, e há um acréscimo de inventividade que se alia ao cotidiano do ensinoaprendizagem. O mentoring permitiu até agora a criação e a sustentação de espaços vigorosos para a discussão e reflexão de temas transversais que apresentam dificuldades de inserção nos planos de ensino.

Esses trabalhos e essas reflexões comporão uma espécie de portfólio do aluno feito para cada um dos internatos. Depois de reunidos e retrabalhados, eles farão parte do que se denomina Memorial Reflexivo. O resultado desse processo é considerado formalmente como o trabalho de conclusão de curso (TCC), o qual é apresentado publicamente e acompanhado pelo mentor, cujos frutos são muito significativos para alunos e docentes. 
Os relatos sobre a experiência de professores mentores é de gratificação pessoal e amadurecimento como docentes, mesmo que existam impasses nesse processo que exige disponibilidade para acompanhar o crescimento amplo dos discentes. Nesse encontro intergeracional, orientado pelo cuidado, observa-se que a cultura do mentoring tem favorecido a constituição de uma nova discursividade, em contraponto ao discurso que naturaliza a formação e o exercício médico como mortificantes.

Há que se considerar também as conexões entre o mentoring e as ações integradas do NAP, especialmente na identificação dos discentes em vulnerabilidade psíquica e sofrimento mental, e no apoio a eles. Essa parceria mostra-se positiva no sentido de evitar tentativas de autoextermínio ao oferecer o acolhimento imediato. O professor mentor tem um papel estratégico na formação e na construção da identidade médica dos alunos, e também na universidade como um todo, principalmente a partir da cultura do cuidado incorporada ao cotidiano das práticas de acolhimento e suporte, tanto no campus quanto fora dele.

\section{CONTRIBUIÇÃO DOS AUTORES}

Todos os autores trabalharam em conjunto em todas as etapas, participando ativa e igualmente na elaboração deste relato de experiência.

\section{CONFLITO DE INTERESSES}

Declaramos não haver conflito de interesses.

\section{FINANCIAMENTO}

Declaramos não haver financiamento.

\section{REFERÊNCIAS}

1. Brasil. Resolução no 3, de 20 de junho de 2014. Institui Diretrizes Curriculares Nacionais do Curso de Graduação em Medicina e dá outras providências. Diário Oficial [da] República Federativa do Brasil; 23 jun 2014 [acesso em 17 mar 2021]. Disponível em: http://portal.mec.gov. br/index.php?option=com_docman\&view=download\&alias $=15874$ rces003-14\&category_slug=junho-2014-pdf\&ltemid=30192.

2. Dyrbye LN, Thomas MR, Shanafelt TD. Systematic review of depression, anxiety, and other indicators of psychological distress among U. S. and Canadian medical students. Acad Med. 2006;81(4):354-73.

3. Bellodi PL, Arruda MM. Tutoria: mentoring na formação médica. São Paulo: Casa do Psicólogo; 2005, p.53.

4. Martins AF, Bellodi PL. Mentoring: uma vivência de humanização e desenvolvimento no curso médico. Interface (Botucatu). 2016;20(58):71526 [acesso em 01 mar 2021]. Disponível em: https://www.scielo.br/pdf/ icse/v20n58/1807-5762-icse-1807-576220150432.pdf.

5. Carvalho AQB. Programas formais de mentoring no Brasil: investigação dos relacionamentos [tese]. São Paulo: Insper; 2015. 51 p. [acesso em 01 mar 2021]. Disponível em: http://dspace.insper.edu.br/xmlui/bitstream/ handle/11224/1321/Adriana\%20Quadros\%20Brant\%20de\%20Carvalho_ Trabalho.pdf?sequence $=1$.

6. Ramanan RA, Taylor WC, Davis RB, Phillips RS. Mentoring matters. Mentoring and career preparation in internal medicine residency training. J Gen Intern Med. 2006;21(4):340-5 [acesso em 01 mar 2021]. Disponível em: https://link. springer.com/article/10.1111\%2Fj.1525-1497.2006.00346.x.

7. Bellodi $\mathrm{PL}$, Chebabo R, Abensur SI, Martins MA. Mentoring: ir ou não ir, eis a questão: um estudo qualitativo. Rev Bras Educ Med. 2011;35(2):23745 [acesso em 01 mar 2021]. Disponível em: https://www.scielo.br/scielo. php?script=sci_arttext\&pid=S0100-55022011000200013.

8. Gonçalves MCN, Bellodi PL. Ser mentor em medicina: uma visão arquetípica das motivações e transformações na jornada. Interface (Botucatu). 2012;16 (41):501-14 [acesso em 01 mar 2021]. Disponível em: https://www.scielo.br/ scielo.php?script=sci_arttext\&pid=S1414-32832012000200016\&lng=en\&n $\mathrm{rm}=\mathrm{iso} \&$ tIng=pt. 